\section{( OPEN ACCESS}

\title{
Headache-related health resource utilisation in chronic and episodic migraine across six countries
}

\author{
Joanna C Sanderson, ${ }^{1,2}$ Emily B Devine, ${ }^{1}$ Richard B Lipton, ${ }^{3}$ Lisa M Bloudek, ${ }^{2}$ \\ Sepideh F Varon, ${ }^{2}$ Andrew M Blumenfeld, ${ }^{4}$ Peter J Goadsby, ${ }^{5}$ Dawn C Buse, ${ }^{3}$ \\ Sean D Sullivan ${ }^{1}$
}

Pharmaceutical Outcomes Research \& Policy Program (PORPP), University of Washington, Seattle, Washington, USA

'Global Health Outcomes Strategy and Research Allergan Inc, Irvine, California, USA

${ }^{3}$ Montefiore Headache Center and the Department of Neurology, Albert Einstein College of Medicine, Bronx, New York, USA

${ }^{4}$ The Neurology Center, Encinitas, California, USA ${ }^{5}$ Headache Group, Department of Neurology, University of California, San Francisco, San Francisco, California, USA

\section{Correspondence to} Joanna C Sanderson, Allergan Inc, 2525 Dupont Drive, Irvine, CA 92612, USA; Sanderson_Joanna@Allergan. com

Received 20 February 2013 Revised 29 April 2013 Accepted 3 June 2013 Published Online First 29 June 2013



To cite: Sanderson $J C$ Devine EB, Lipton RB, et al. J Neurol Neurosurg Psychiatry 2013:84: 1309-1317.

\section{ABSTRACT \\ Objective To describe headache-related health} resource usage in chronic and episodic migraine across six countries.

Methods A web-based questionnaire eliciting data on several topics, including health resource usage, was administered to panellists with migraine from the USA, Canada, UK, Germany, France and Australia.

Respondents were grouped into episodic and chronic migraine, based on reported headache phenotype and headache-day frequency. ORs were calculated, comparing usage in each country to that in the US, controlling for chronic versus episodic migraine and other factors.

Results Relative to the USA, the odds of visiting a provider for headache during the preceding 3 months were significantly higher in all countries, except Germany. Respondents in France were more likely to report having a provider they typically visited for headache-related care. The odds of visiting the emergency department for headache were significantly lower in France, the UK and Germany, and hospitalisation for headache was significantly more frequent in Canada and Australia. Respondents from all countries, except Canada, were more likely to report currently using a prescription-acute treatment, and those from France were more likely to report trying more than three acute treatments. Preventive treatment use did not differ significantly.

Conclusions Headache-related resource usage differed significantly between the USA and other countries. US respondents were generally less likely to report recent provider visits and use of prescription-acute treatments. They were more likely to report emergency department visits than in European countries, but less likely to report hospitalisation than in Canada and Australia.

\section{BACKGROUND}

Migraine is a brain disorder most clearly manifested by headache. The two major forms are distinguished based on headache frequency: episodic migraine (EM) and chronic migraine (CM). The revised second International Classification of Headache Disorders (ICHD-IIR) defines CM as having 15 or more headache-days per month for 3 months, with at least eight headaches per month linked to migraine without aura, either by virtue of meeting a case definition or by response to migraine-specific treatment. ${ }^{1} \mathrm{EM}$ is characterised by headache on $<15$ days per month with one or more attacks fulfilling ICHD-II criteria. ${ }^{2} \mathrm{CM}$ affects approximately $1-2 \%$ of the worldwide population and has a significantly greater effect on quality of life than EM. ${ }^{3}{ }^{4} \mathrm{CM}$ patients are more debilitated and more likely to miss work or have decreased productivity. ${ }^{5-7} \mathrm{CM}$ patients have more comorbid conditions, including psychiatric and pain disorders. ${ }^{5} 8$ They also use more health resources than EM patients, including emergency department (ED) visits, clinic visits and medications. 59

Although studies have consistently revealed variation in resource usage between CM and EM, less is known about how this compares across countries. The first International Burden of Migraine Study (IBMS-I) revealed that chronic migraineurs used more health resources than episodic migraineurs in the USA, Canada, UK, France, Germany, Italy and Spain. ${ }^{9}{ }^{10}$ However, these publications focused primarily on comparing $\mathrm{CM}$ to EM rather than comparing countries. Gerth et $a l^{11}$ found that migraine-based resource usage was comparable across the 25 countries included in their study. However, sample sizes were small for some countries (eg, <20 cases), and statistical tests were only used to compare usage across large international regions. The study also excluded subjects reporting $>8$ migraine attacks per month, which may have excluded the majority of those with CM. Finally, the study is over 10 years old, and migraine awareness and prevention and treatment strategies may have changed in this time.

Healthcare systems vary in many ways that could influence healthcare access and usage, including supply and demand factors, such as type of insurance (public or private), covered benefits, percent of population insured, physician reimbursement, out-of-pocket expenses and accessibility (eg, physician supply and wait times). ${ }^{12}$ Results from a study investigating access to care revealed that, of 11 countries (Australia, Canada, France, Germany, The Netherlands, New Zealand, Norway, Sweden, Switzerland, the UK and the USA), subjects from the USA were most likely to report that in the last year they: (1) had problems paying medical bills, (2) had out-of-pocket-expenses exceeding US $\$ 1000$, (3) skipped medication doses due to cost, and (4) did not receive recommended care due to cost. Patients from the USA also reported the least confidence in their ability to pay for medical expenditures. Conversely, US cases were less likely 
than those from other countries, except Switzerland and Germany, to report waiting for 2 months or more to see a specialist. ${ }^{12}$ While other country-specific factors, such as cultural and economic differences, may influence health resource usage, much of this difference could be accounted for by the contrast between universal government-sponsored healthcare and private insurance-based healthcare.

The objective of this research is to describe differences in headache-related resource usage, including both health services and medication use, among chronic and episodic migraineurs in the USA, Canada, the UK, Germany, France and Australia.

\section{METHODS}

\section{Design and data source}

The second international burden of migraine study (IBMS-II) investigated the burden of CM and EM in the USA, Canada, the UK, Germany, France and Australia. A web-based screening survey, used to determine eligibility, was administered to 32782 Lightspeed Research panellists who previously reported experiencing headaches or migraines. This panel consists of individuals from several countries who express interest in and register online to complete health-related surveys for nominal compensation. ${ }^{13}$ Target sample sizes were equal for CM and EM but differed by country.

Screener respondents $(n=16663)$ were eligible for the main questionnaire if they were $\geq 18$ years of age and reported at least one headache during the prior 3 months that was not associated with a cold, flu, head injury, or hangover. Additionally, respondents must have reported symptoms meeting the ICHD-IIR diagnostic criteria for migraine, based on the following two requirements. ${ }^{1}$ First, they must report that for either their most severe or second most severe headache type, they experienced at least two of the following symptoms 'half the time or more' or 'less than half the time:' (1) moderate to severe pain, (2) throbbing pain, (3) pain worsening with routine physical activity, or (4) unilateral pain. Second, they must report that for either their most severe or second most severe headache type, they experienced at least one of the following symptoms 'half the time or more' or 'less than half the time:' (1) nausea, or (2) photophobia and phonophobia. Eligible respondents $(n=1183)$ were divided into two groups, CM and EM, based on average reported headache-day frequency on the screener survey (EM: $<15$ headache days per month, CM: $\geq 15$ headache days per month).

The web-based main questionnaire collected data concerning sociodemographic and clinical characteristics, comorbid conditions, attitudes and usage of health resources. Participants reported use of the following resources for headache: provider visits, ED visits, hospital admissions and acute and preventive medications.

IBMS-II was approved by a central ethics review board (Institutional Review Board Services, Ontario, Canada). This research was conducted with approval from the Institutional Review Board of the University of Washington.

\section{Statistical analyses}

Because CM patients were oversampled and sampling differed by country, we stratified all analyses by CM versus EM and country. Sociodemographic and clinical characteristics were analysed using means and SDs for continuous variables and proportions for categorical variables.

We performed inferential analyses to test the association between country and usage of specific health resources. Bivariate inferential analyses allowed for simple descriptions of relationships. We used analysis of variance to determine whether means of continuous variables varied across countries, and $\chi^{2}$ tests to determine whether the proportion of respondents reporting use of a given resource differed by country.

Multivariate logistic regression was used to determine whether the odds of reporting use of a given resource differed by country, relative to the USA, while controlling for covariates. Outcome variables were dichotomised, if necessary. Models included the following covariates, which were selected a priori: age, gender, income (above or below country-specific median), race/ethnicity (Caucasian, black, Asian, Hispanic, other/prefer not to say), residential population density (urban, suburban, rural), employment status (working, not working, student, homemaker, prefer not to say), Body Mass Index (BMI) category (underweight $<18.5$, normal 18.5-24.9, overweight 25.0-29.9, obese >30.0), EM versus CM, and number of comorbid conditions. All statistical analyses were completed using STATA V.12 (College Station, Texas, USA). ${ }^{14}$

\section{RESULTS}

Of the eligible screener respondents $(n=1183), 1165 \quad(98 \%)$ completed the main questionnaire. Tables 1 and 2 present sociodemographic and clinical characteristics of the CM and the EM groups.

\section{Sociodemographic characteristics}

For the CM group, mean age ranged by country from 38 to 46 years. For EM, mean age was similar, ranging from 41 to 48 years. Respondents were predominantly female in all countries and both migraine types (CM and EM). Gender distribution varied significantly by country in EM only; Australia had the lowest proportion that was female (56\%) and Canada had the highest $(84 \%)$. Over $80 \%$ of respondents were Caucasian in all countries and both migraine types, except CM respondents in Germany (65\%). Race/ethnicity varied significantly by country, but this may have been driven by the proportion of German respondents reporting 'other' or 'prefer not to say.' Reported residential population density also varied significantly by country in both migraine types; USA, UK and Australia reported the most suburban living; Canada and Germany reported more urban living; France was split between urban and rural. CM respondents were less likely to report being currently employed in all countries. Employment status varied significantly by country in EM only; US and Australian respondents were less likely to report working full or part time and more likely to report being a homemaker than those from other countries. In all countries, fewer CM respondents than EM respondents reported an annual income above the country-specific median, but this did not differ significantly by country within migraine types.

\section{Comorbidities and disability}

BMI category, number of comorbidities and Migraine Disability Assessment Score (MIDAS) grade did not differ among countries for CM. ${ }^{15}$ Among respondents with EM, BMI and MIDAS grade differed significantly by country. More CM respondents were classified as obese (BMI>30.0) than EM respondents in all countries, except for the USA and the UK, where the proportion of the obese was similar across migraine types. BMI distribution differed significantly by country in EM respondents, with the highest prevalence of obesity in the USA (40\%) and the lowest in France (14\%). The number of comorbidities was also higher in CM respondents but did not differ significantly by country. The MIDAS grade was higher, indicating more 
Table 1 Sociodemographic and clinical characteristics of chronic migraineurs by country

\begin{tabular}{|c|c|c|c|c|c|c|c|}
\hline $\begin{array}{l}\text { Characteristic } \\
\text { n (\%), unless otherwise stated }\end{array}$ & $\begin{array}{l}\text { USA } \\
(n=205)\end{array}$ & $\begin{array}{l}\text { Canada } \\
(\mathrm{n}=50)\end{array}$ & $\begin{array}{l}\text { France } \\
(n=57)\end{array}$ & $\begin{array}{l}\text { UK } \\
(n=50)\end{array}$ & $\begin{array}{l}\text { Germany } \\
(\mathrm{n}=81)\end{array}$ & $\begin{array}{l}\text { Australia } \\
(n=50)\end{array}$ & p Value* \\
\hline Age in years, mean (SD) & $44(12)$ & $46(11)$ & $44(12)$ & $43(13)$ & $38(12)$ & $45(10)$ & $<0.01$ \\
\hline Female & $166(81)$ & $39(78)$ & $42(74)$ & $39(78)$ & $67(83)$ & $39(78)$ & 0.82 \\
\hline Income $>$ country-specific median & $83(42)$ & $17(40)$ & $17(32)$ & $17(37)$ & $20(28)$ & $17(39)$ & 0.38 \\
\hline \multicolumn{8}{|l|}{ Race/ethnicity } \\
\hline Caucasian/white (includes Arab/Middle Eastern) & $178(87)$ & $45(90)$ & $52(91)$ & $44(88)$ & $53(65)$ & $49(98)$ & \multirow[t]{5}{*}{$<0.01$} \\
\hline Black & $9(4)$ & $1(2)$ & $2(4)$ & $0(0)$ & $1(1)$ & $0(0)$ & \\
\hline Asian & $3(1)$ & $0(0)$ & $0(0)$ & $6(12)$ & $0(0)$ & $0(0)$ & \\
\hline Hispanic or Latino/Latin American & $7(3)$ & $0(0)$ & $0(0)$ & $0(0)$ & $0(0)$ & $0(0)$ & \\
\hline Other or prefer not to say & $8(4)$ & $4(8)$ & $3(5)$ & $0(0)$ & $27(33)$ & $1(2)$ & \\
\hline \multicolumn{8}{|l|}{ Residential population density } \\
\hline Urban & $41(20)$ & $25(50)$ & $21(37)$ & $14(28)$ & $45(56)$ & 7 (14) & \multirow[t]{3}{*}{$<0.01$} \\
\hline Suburban & $99(48)$ & $17(34)$ & $17(30)$ & $24(48)$ & $19(23)$ & $30(60)$ & \\
\hline Rural & $65(32)$ & $8(16)$ & $19(33)$ & $12(24)$ & $19(21)$ & $13(26)$ & \\
\hline \multicolumn{8}{|l|}{ Work status } \\
\hline Working full or part time & $78(38)$ & $19(38)$ & $21(37)$ & $25(50)$ & $45(56)$ & $18(36)$ & \multirow[t]{5}{*}{0.12} \\
\hline $\begin{array}{l}\text { Unemployed (retired, disabled, seeking } \\
\text { employment) }\end{array}$ & $93(45)$ & $23(46)$ & $24(42)$ & $19(38)$ & $24(30)$ & $23(46)$ & \\
\hline Student & $3(1)$ & $3(6)$ & $2(3)$ & $0(0)$ & $3(4)$ & $3(6)$ & \\
\hline Homemaker & $30(15)$ & $5(10)$ & $9(16)$ & $4(8)$ & $9(11)$ & $6(12)$ & \\
\hline Prefer not to say & $1(1)$ & $0(0)$ & $1(2)$ & $2(4)$ & $0(0)$ & $0(0)$ & \\
\hline \multicolumn{8}{|l|}{ BMI category } \\
\hline Underweight $(<18.5)$ & $6(3)$ & $1(2)$ & $1(2)$ & $5(10)$ & $5(6)$ & $2(4)$ & \multirow[t]{4}{*}{0.20} \\
\hline Normal (18.5-24.9) & $62(30)$ & $14(28)$ & $25(44)$ & $16(32)$ & $23(28)$ & $9(18)$ & \\
\hline Overweight (25.0-29.9) & $55(27)$ & $14(28)$ & $12(21)$ & $16(32)$ & $24(30)$ & $14(28)$ & \\
\hline Obese $(>30.0)$ & $82(40)$ & $21(42)$ & $19(33)$ & $13(26)$ & $29(36)$ & $25(50)$ & \\
\hline \multicolumn{8}{|l|}{ Number of comorbid conditions } \\
\hline 0 & $21(10)$ & $3(6)$ & $5(9)$ & $7(14)$ & $4(5)$ & $3(6)$ & \multirow[t]{4}{*}{0.13} \\
\hline 1 & $27(13)$ & $2(4)$ & $10(18)$ & $4(8)$ & $12(15)$ & $3(6)$ & \\
\hline 2 & $30(15)$ & $8(16)$ & $3(5)$ & $9(18)$ & $13(16)$ & $3(6)$ & \\
\hline$>2$ & $127(62)$ & $37(74)$ & $39(68)$ & $30(60)$ & $52(64)$ & $41(82)$ & \\
\hline \multicolumn{8}{|l|}{ MIDAS grade } \\
\hline Grade I (little disability) & $10(5)$ & $1(2)$ & $5(9)$ & $1(2)$ & $4(5)$ & $3(6)$ & \multirow[t]{5}{*}{0.38} \\
\hline Grade II (mild disability) & $12(6)$ & $2(4)$ & $3(5)$ & $2(4)$ & $1(1)$ & $4(8)$ & \\
\hline Grade III (moderate disability) & $10(5)$ & $2(4)$ & $6(10)$ & $3(6)$ & $3(4)$ & $4(8)$ & \\
\hline Grade IVa (severe disability) & $33(16)$ & $4(8)$ & $11(19)$ & $8(16)$ & $11(14)$ & $2(4)$ & \\
\hline Grade IVb (very severe disability) & $140(68)$ & $41(82)$ & $32(56)$ & $36(72)$ & $62(77)$ & $37(74)$ & \\
\hline
\end{tabular}

${ }^{*} p$ Value for age from analysis of variance test (all others from $\chi^{2}$ tests).

BMI, Body Mass Index $\left(\mathrm{kg} / \mathrm{m}^{2}\right)$; MIDAS, Migraine Disability Assessment Score.

severe disability, in CM respondents than EM respondents; MIDAS grade distribution varied significantly by country in EM respondents only.

\section{Resource use for headache}

Headache-related resource usage is presented in table 3 for CM and in table 4 for EM. Resource usage was generally higher in $\mathrm{CM}$ than in EM. The proportion of respondents who reported visiting a healthcare provider for headache in the 3 months prior to survey completion differed significant by country in $\mathrm{CM}$ only. However, in both CM and EM, respondents from Australia reported the highest proportion of headache-related provider visits in the prior 3 months (CM 64\%, EM 36\%), and respondents from the USA reported the lowest (CM 37\%, EM 19\%). The proportion of respondents who reported ever visiting the ED for headache differed significantly by country in both CM and EM, with respondents from Canada reporting the highest proportion (CM 52\%, EM 35\%) and respondents from the UK reporting the lowest (CM 14\%, EM 8\%). Similarly, the proportion of EM respondents reporting ever being admitted to the hospital for headache differed significantly by country, with Canada having the highest proportion (16\%) and the UK having none; hospital admission did not differ significantly in CM. The proportion of respondents who reported having a healthcare provider whom they typically visited for headache-related care did not differ significantly by country in either migraine type. The number of preventive treatments ever tried, and the number currently used, also did not differ significantly by country in either CM or EM (also see figures 1 and 2). Antidepressants were the most commonly reported preventive agent currently used in all countries and both migraine types, except EM respondents from Germany, who reported a higher proportion of current $\beta$-blocker use. Most respondents reported trying more than three acute treatments, and the number ever tried did not differ significantly by country in either CM or EM. Use of over-the-counter acute treatments was more commonly reported than use of prescription-acute treatments in all countries and migraine types, except $\mathrm{CM}$ respondents from 
Table 2 Sociodemographic and clinical characteristics of episodic migraineurs by country

\begin{tabular}{|c|c|c|c|c|c|c|c|}
\hline $\begin{array}{l}\text { Characteristic } \\
\text { n (\%), unless otherwise stated }\end{array}$ & $\begin{array}{l}\text { USA } \\
(n=226)\end{array}$ & $\begin{array}{l}\text { Canada } \\
(n=55)\end{array}$ & $\begin{array}{l}\text { France } \\
(n=109)\end{array}$ & $\begin{array}{l}\text { UK } \\
(n=107)\end{array}$ & $\begin{array}{l}\text { Germany } \\
(n=112)\end{array}$ & $\begin{array}{l}\text { Australia } \\
(n=63)\end{array}$ & p Value* \\
\hline Age in years, mean (SD) & $44(12)$ & $43(12)$ & $43(12)$ & $48(12)$ & $44(12)$ & $41(13)$ & $<0.01$ \\
\hline Female & $181(80)$ & $46(84)$ & $84(77)$ & $73(68)$ & $63(56)$ & $35(56)$ & $<0.01$ \\
\hline Income above country-specific median & $117(54)$ & $22(47)$ & $45(47)$ & $42(42)$ & $52(53)$ & $30(54)$ & 0.46 \\
\hline \multicolumn{8}{|l|}{ Race/ethnicity } \\
\hline Caucasian/white (includes Arab/Middle Eastern) & $198(88)$ & $53(96)$ & $104(95)$ & $103(96)$ & $94(84)$ & $60(95)$ & \multirow[t]{5}{*}{$<0.01$} \\
\hline Black & $10(4)$ & $1(2)$ & $0(0)$ & $0(0)$ & $0(0)$ & $0(0)$ & \\
\hline Asian & $5(2)$ & $1(2)$ & $1(1)$ & $2(2)$ & $0(0)$ & $1(2)$ & \\
\hline Hispanic or Latino/Latin American & $10(4)$ & $0(0)$ & $1(1)$ & $0(0)$ & $1(1)$ & $0(0)$ & \\
\hline Other or prefer not to say & $3(1)$ & $0(0)$ & $3(3)$ & $2(2)$ & $17(15)$ & $2(3)$ & \\
\hline \multicolumn{8}{|l|}{ Residential population density } \\
\hline Urban & $51(23)$ & $33(60)$ & $37(34)$ & $28(26)$ & $69(62)$ & $15(24)$ & \multirow[t]{3}{*}{$<0.01$} \\
\hline Suburban & $118(52)$ & $13(24)$ & $27(25)$ & $42(39)$ & $26(23)$ & $31(49)$ & \\
\hline Rural & $57(25)$ & $9(16)$ & $45(41)$ & $37(35)$ & $17(15)$ & $17(27)$ & \\
\hline \multicolumn{8}{|l|}{ Work status } \\
\hline Working full or part time & $125(55)$ & $33(60)$ & $68(62)$ & $67(63)$ & $67(60)$ & $26(41)$ & \multirow[t]{5}{*}{$<0.01$} \\
\hline $\begin{array}{l}\text { Unemployed (retired, disabled, seeking } \\
\text { employment) }\end{array}$ & $45(20)$ & $11(20)$ & $20(18)$ & $24(22)$ & $25(22)$ & $21(33)$ & \\
\hline Student & $15(7)$ & $1(2)$ & $8(7)$ & $0(0)$ & $7(6)$ & $1(2)$ & \\
\hline Homemaker & $41(18)$ & $7(13)$ & $13(12)$ & $13(12)$ & $13(12)$ & $14(22)$ & \\
\hline Prefer not to say & $0(0)$ & $3(5)$ & $0(0)$ & $3(3)$ & $0(0)$ & $1(2)$ & \\
\hline \multicolumn{8}{|l|}{ BMI category } \\
\hline Underweight (<18.5) & $2(1)$ & $1(2)$ & $8(7)$ & $6(6)$ & $4(4)$ & $2(3)$ & \multirow[t]{4}{*}{$<0.01$} \\
\hline Normal (18.5-24.9) & $70(31)$ & $20(36)$ & $47(43)$ & $42(39)$ & $43(38)$ & $19(30)$ & \\
\hline Overweight (25.0-29.9) & $63(28)$ & $14(25)$ & $39(36)$ & $29(27)$ & $36(32)$ & $20(32)$ & \\
\hline Obese $(>30.0)$ & $91(40)$ & $20(36)$ & $15(14)$ & $30(28)$ & $29(26)$ & $22(35)$ & \\
\hline \multicolumn{8}{|l|}{ Number of comorbid conditions } \\
\hline 0 & $36(16)$ & $8(15)$ & $18(16)$ & $17(16)$ & $22(20)$ & $11(17)$ & \multirow[t]{4}{*}{0.83} \\
\hline 1 & $48(21)$ & $11(20)$ & $19(17)$ & $19(18)$ & $26(23)$ & $10(16)$ & \\
\hline 2 & $40(18)$ & $11(20)$ & $22(20)$ & $20(19)$ & $10(9)$ & $9(14)$ & \\
\hline$>2$ & $102(45)$ & $25(45)$ & $50(46)$ & $51(48)$ & $54(48)$ & $33(52)$ & \\
\hline \multicolumn{8}{|l|}{ MIDAS grade } \\
\hline Grade I (little disability) & $41(18)$ & $19(35)$ & $27(25)$ & $31(29)$ & $13(12)$ & $14(22)$ & \multirow[t]{5}{*}{0.02} \\
\hline Grade II (mild disability) & $54(24)$ & $15(27)$ & $28(26)$ & $31(29)$ & $22(20)$ & $23(36)$ & \\
\hline Grade III (moderate disability) & $71(31)$ & $9(16)$ & $31(28)$ & $24(22)$ & $45(40)$ & $13(21)$ & \\
\hline Grade IVa (severe disability) & $46(20)$ & $9(16)$ & $18(16)$ & $17(16)$ & $23(20)$ & $8(13)$ & \\
\hline Grade IVb (very severe disability) & $14(6)$ & $3(5)$ & $5(5)$ & $4(4)$ & $9(8)$ & $5(8)$ & \\
\hline
\end{tabular}

${ }^{*} p$ Value for age from analysis of variance test (all others from $\chi^{2}$ tests).

BMI, Body Mass Index $\left(\mathrm{kg} / \mathrm{m}^{2}\right)$; MIDAS, Migraine Disability Assessment Score.

Germany, who reported greater use of prescription-acute treatments. The proportion of subjects reporting current use of prescription-acute treatment was lowest in Canada for EM $(44 \%)$ and in the USA for CM (53\%), and highest in the UK for EM (71\%), and in Australia for CM (76\%).

Table 5 and figure 3 present the type of provider respondents reported typically visiting for headache care. Respondents could report multiple provider types. Primary care providers were the most commonly reported provider of headache care in all countries and migraine types. For CM, Australia had the highest proportion of respondents who reported typically visiting a primary care provider (88\%), and Canada had the lowest $(56 \%)$. For EM, France had the highest proportion of respondents who reported typically visiting a primary care provider (74\%), and the USA had the lowest (57\%). Neurologists were the second most commonly reported provider of headache care in all countries, except Australia, where chiropractors were reported with equal frequency in $\mathrm{CM}$ and greater frequency in EM. In both CM and EM, the proportion of respondents who reported typically visiting primary care providers, chiropractors and internists differed significantly by country. The proportion of respondents who reported typically visiting a neurologist differed significantly in EM only.

Table 6 presents the results from the multivariate analyses of resource usage. All ORs are relative to the USA and adjusted for age, gender, income, race/ethnicity, region of residence, employment status, BMI, migraine type and number of comorbid conditions. The odds of visiting a provider for headache in the 3 months prior to survey completion were higher in all countries relative to the USA; this was significant for all countries except Germany. Respondents from other countries were also more likely to report having a healthcare provider whom they typically visited for headache-related care, though this was only significant for France. The odds of ever having visited the ED for headache were significantly lower in France, the UK and Germany. Respondents from Canada and Australia did not differ significantly from the USA in ED visits, but they were significantly more likely to report ever being admitted to the 
Table 3 Resource utilisation amongst chronic migraineurs by country

\begin{tabular}{|c|c|c|c|c|c|c|c|}
\hline \multirow[b]{2}{*}{ Resources used } & \multicolumn{7}{|l|}{ n (\%) } \\
\hline & USA $(n=205)$ & Canada $(n=50)$ & France $(n=57)$ & UK $(n=50)$ & Germany $(n=81)$ & Australia $(n=50)$ & p Value* \\
\hline Visited a provider for HA in the last 3 months & $76(37)$ & $23(46)$ & $31(54)$ & $26(52)$ & 37 (46) & $32(64)$ & 0.009 \\
\hline Have a typical HA care providert & $177(86)$ & $44(88)$ & $52(91)$ & $42(84)$ & $73(90)$ & $48(96)$ & 0.379 \\
\hline Have visited the ED for $\mathrm{HA}$ & $87(42)$ & $26(52)$ & $9(16)$ & $7(14)$ & $13(16)$ & $19(38)$ & $<0.001$ \\
\hline Have been admitted to hospital for HA & $28(14)$ & $11(22)$ & $10(17)$ & $7(14)$ & $11(14)$ & $12(24)$ & 0.398 \\
\hline \multicolumn{8}{|l|}{ Number of migraine preventive agents ever tried } \\
\hline 0 & $84(41)$ & $25(50)$ & $20(35)$ & $13(26)$ & 29 (36) & $12(24)$ & 0.122 \\
\hline 1 & 29 (14) & $8(16)$ & $11(19)$ & $8(16)$ & $15(18)$ & $12(24)$ & \\
\hline 2 & $25(12)$ & $2(4)$ & $5(9)$ & $12(24)$ & $11(14)$ & $12(24)$ & \\
\hline 3 & $14(7)$ & $2(4)$ & $6(10)$ & $3(6)$ & $9(11)$ & $2(4)$ & \\
\hline$>3$ & $53(26)$ & $13(26)$ & $15(26)$ & $14(28)$ & $17(21)$ & $12(24)$ & \\
\hline \multicolumn{8}{|l|}{ Number of migraine preventive agents currently used } \\
\hline 0 & $127(62)$ & $30(60)$ & $35(61)$ & $26(52)$ & $53(65)$ & $24(48)$ & 0.387 \\
\hline 1 & $57(28)$ & $17(34)$ & $16(28)$ & $15(30)$ & $23(28)$ & $21(42)$ & \\
\hline$>1$ & $21(10)$ & $3(6)$ & $6(10)$ & $9(18)$ & $5(6)$ & $5(10)$ & \\
\hline \multicolumn{8}{|l|}{ Type of migraine preventive agent(s) currently used $\neq$} \\
\hline Antidepressant & $59(29)$ & $12(24)$ & $15(26)$ & $18(36)$ & $20(25)$ & $17(34)$ & $\mathrm{N} / \mathrm{A}$ \\
\hline Antiepileptic & $26(13)$ & 7 (14) & $5(9)$ & $5(10)$ & $6(7)$ & $10(20)$ & \\
\hline$\beta$ Blocker & $10(5)$ & $2(4)$ & $10(17)$ & $9(18)$ & $7(9)$ & $3(6)$ & \\
\hline Calcium channel blocker & $5(2)$ & $0(0)$ & $1(2)$ & $2(4)$ & $1(1)$ & $1(2)$ & \\
\hline \multicolumn{8}{|l|}{ Number of migraine acute agents ever tried } \\
\hline$\leq 3$ & $32(16)$ & $9(18)$ & $5(9)$ & $9(18)$ & $13(16)$ & $3(6)$ & 0.326 \\
\hline$>3$ & $173(84)$ & $41(82)$ & $52(91)$ & $41(82)$ & $68(84)$ & 47 (94) & \\
\hline \multicolumn{8}{|l|}{ Type of migraine acute agent(s) currently used $\neq$} \\
\hline Prescription & $108(53)$ & $35(70)$ & $39(68)$ & $34(68)$ & $58(72)$ & $38(76)$ & $\mathrm{N} / \mathrm{A}$ \\
\hline OTC & $170(83)$ & $38(76)$ & $43(75)$ & $35(70)$ & $50(62)$ & $44(88)$ & \\
\hline
\end{tabular}

${ }^{*} p$ Values from $\chi^{2}$ tests.

†Subjects who report that they have a healthcare provider who they typically visit for headache-related care.

¥Subjects may be using more than one agent.

$E D$, emergency department; HA, headache; N/A, not available (some respondents taking more than one agent); OTC, over the counter.

hospital for headache. The odds of currently using a prescription-acute treatment were significantly higher in all countries, except Canada, and respondents from France were more likely to report ever trying more than three acute treatments. The number of preventive treatment currently or ever used did not differ significantly from the USA.

\section{DISCUSSION}

As in prior studies, we found a female preponderance both for CM and EM. ${ }^{4} 16$ The CM group was slightly older, reported lower household income, was less likely to be employed, reported a greater number of comorbid conditions and had higher MIDAS scores, signifying more severe headache-related disability. EM respondents were more diverse across countries sociodemographically and clinically than CM respondents. Because chronic migraineurs constitute the most debilitated subset of the migraine population, they may represent a distinct group clinically and, consequently, may share more characteristics than do episodic migraineurs.

Resource usage differed significantly by country. By comparison with the USA, respondents from other countries were more likely to report visiting a healthcare provider for headache in the prior 3 months, in both unadjusted and adjusted analyses. Similarly, US respondents were less likely to report having a healthcare provider whom they typically visited for headache care, though adjusted results were only significant compared with France. This trend is consistent with IBMS-I, in which $26 \%$ of US respondents reported visiting a primary care provider in the past 3 months, compared with $48 \%$ in Canada, $56 \%$ in the UK, 60\% in France and 48\% in Germany. ${ }^{9} 10$ These differences are likely multifactorial. Many factors may limit healthcare access in the US, such as the lack of universal coverage or the presence of insurance deductibles for preventive services. In general, less access to preventive services could shift health resource usage to emergency services.

Consistent with this idea, US respondents were more likely to report ever visiting the ED for headache than respondents from France, the UK and Germany, in both unadjusted and adjusted analyses. However, Canada actually had the highest percent of $\mathrm{CM}$ subjects who reported visiting the ED for headache. This aligns with the results of a recent study, which found that, out of 11 countries surveyed, Canada had the highest proportion of cases who reported visiting the ED in the prior 2 years. ${ }^{12}$ Our results also indicate that Canadian and Australian respondents were more likely to report ever being admitted to the hospital for migraine than US respondents. Again, the reason for this difference is unknown. Australians and Canadians have longer average wait times to see specialists than those in the USA; the abovementioned study reported that $41 \%$ of respondents in Canada and 28\% in Australia waited 2 months or more to visit a specialist, compared with $9 \%$ in the USA. ${ }^{12}$ Further research into the impact of healthcare system design on access to and use of primary care, tertiary care and emergency services in the migraine population is warranted.

The proportion of respondents who reported ever using migraine preventive therapy ranged from $50 \%$ to $76 \%$ for $\mathrm{CM}$ 
Table 4 Resource usage among episodic migraineurs by country

\begin{tabular}{|c|c|c|c|c|c|c|c|}
\hline \multirow[b]{2}{*}{ Resources used } & \multicolumn{7}{|l|}{ n (\%) } \\
\hline & USA $(n=226)$ & Canada $(n=55)$ & France $(n=109)$ & UK $(n=107)$ & Germany $(n=112)$ & Australia $(n=63)$ & p Value* \\
\hline Visited a provider for HA in the last 3 months & $44(19)$ & $16(29)$ & $30(27)$ & $28(26)$ & $29(26)$ & $23(36)$ & 0.108 \\
\hline Have a typical HA care providert & $166(73)$ & $44(80)$ & $91(83)$ & $82(77)$ & $88(79)$ & $50(79)$ & 0.439 \\
\hline Have visited the ED for $\mathrm{HA}$ & $61(27)$ & $19(35)$ & $15(14)$ & $9(8)$ & $13(12)$ & $17(27)$ & $<0.001$ \\
\hline Have been admitted to hospital for HA & $13(6)$ & $9(16)$ & $13(12)$ & $0(0)$ & $11(10)$ & $7(11)$ & 0.001 \\
\hline \multicolumn{8}{|l|}{ Number of migraine preventive agents ever tried } \\
\hline 0 & $139(61)$ & $37(67)$ & $62(57)$ & $59(55)$ & $67(60)$ & $40(63)$ & 0.978 \\
\hline 1 & $40(18)$ & $5(9)$ & $18(16)$ & $21(20)$ & $20(18)$ & $11(18)$ & \\
\hline 2 & $20(9)$ & $6(11)$ & $16(15)$ & $13(12)$ & $11(10)$ & $4(6)$ & \\
\hline 3 & $7(3)$ & $1(2)$ & $4(4)$ & $4(4)$ & $2(2)$ & $2(3)$ & \\
\hline$>3$ & $20(9)$ & $6(11)$ & $9(8)$ & $10(9)$ & $12(11)$ & $6(9)$ & \\
\hline \multicolumn{8}{|c|}{ Number of migraine preventive agents currently used } \\
\hline 0 & $179(79)$ & $41(75)$ & $81(74)$ & $79(74)$ & $84(75)$ & $48(76)$ & 0.981 \\
\hline 1 & $38(17)$ & $11(20)$ & $21(19)$ & $24(22)$ & $22(20)$ & $12(19)$ & \\
\hline$>1$ & $9(4)$ & $3(5)$ & $7(6)$ & $4(4)$ & $6(5)$ & $3(5)$ & \\
\hline \multicolumn{8}{|c|}{ Type of migraine preventive agent(s) currently used } \\
\hline Antidepressant & $32(14)$ & $9(16)$ & $17(16)$ & $17(16)$ & $15(13)$ & $11(17)$ & $\mathrm{N} / \mathrm{A}$ \\
\hline Antiepileptic & $13(6)$ & $4(7)$ & $6(5)$ & $3(3)$ & $1(1)$ & $2(3)$ & \\
\hline$\beta$ Blocker & $8(3)$ & $4(7)$ & $11(10)$ & $10(9)$ & $18(16)$ & $3(5)$ & \\
\hline Calcium channel blocker & $4(2)$ & $0(0)$ & $2(2)$ & $2(2)$ & $3(3)$ & $1(2)$ & \\
\hline \multicolumn{8}{|l|}{ Number of migraine acute agents ever tried } \\
\hline$\leq 3$ & $62(27)$ & $17(31)$ & $16(15)$ & $22(21)$ & $21(19)$ & $14(22)$ & 0.067 \\
\hline$>3$ & $164(73)$ & $38(69)$ & $93(85)$ & $85(79)$ & $91(81)$ & $49(78)$ & \\
\hline \multicolumn{8}{|l|}{ Type of migraine acute agent(s) currently used‡ } \\
\hline Prescription & $106(47)$ & $24(44)$ & $68(62)$ & $76(71)$ & $68(61)$ & $35(56)$ & N/A \\
\hline OTC & $192(85)$ & $53(96)$ & $81(74)$ & $78(73)$ & $82(73)$ & 54 (86) & \\
\hline
\end{tabular}

and from $33 \%$ to $45 \%$ for EM. Ever use of preventive therapy for EM respondents in the USA was similar to that in respondents from the American Migraine Prevalence and Prevention (AMPP) study, a longitudinal population-based survey study of
US migraineurs (IBMS-II 38\%, AMPP 39\%). ${ }^{17}$ The proportion of CM respondents who reported currently using migraine preventive therapy ranged from $35 \%$ to $52 \%$, depending on the country. These rates are generally higher than those reported in

Episodic Migraine

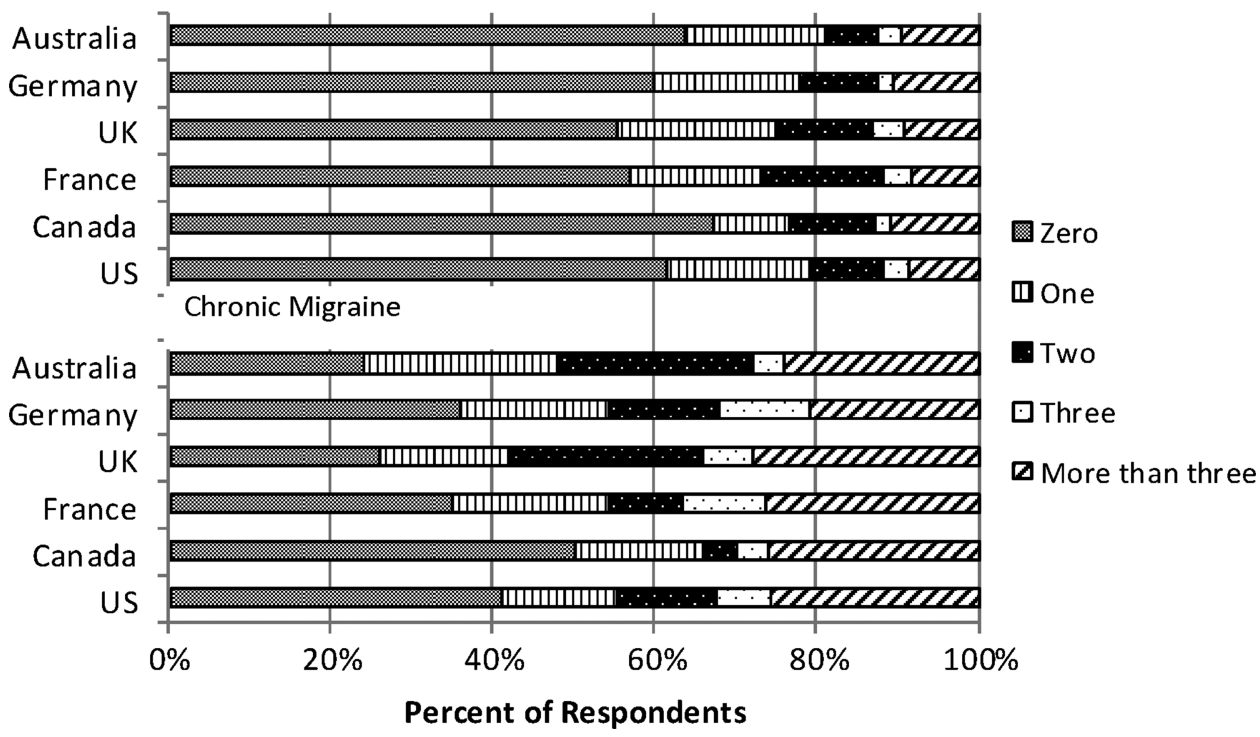

Figure 1 Number of migraine preventive therapies ever used by country. 
Episodic Migraine

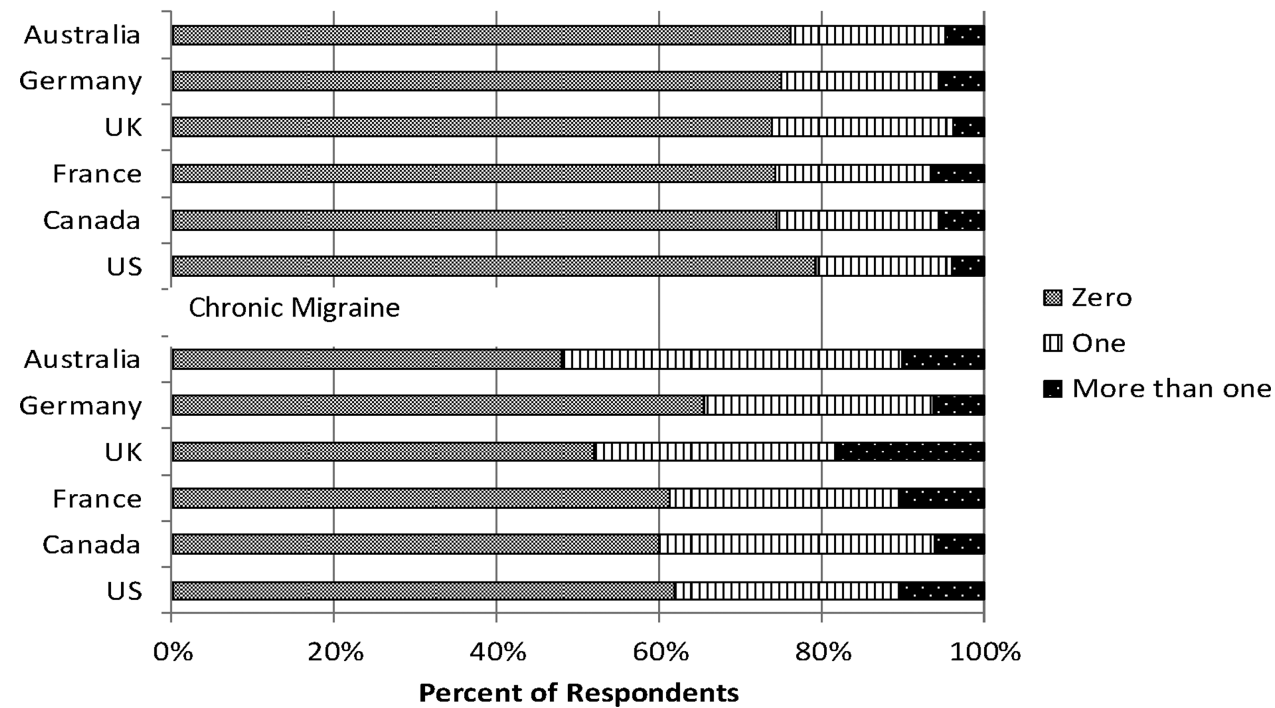

Figure 2 Number of migraine preventive therapies currently used by country.

IBMS-I, in which $4 \%$ to $37 \%$ of $\mathrm{CM}$ respondents reported current preventive treatment use. ${ }^{9}{ }^{10}$ However, given that nearly all $\mathrm{CM}$ patients qualify for migraine preventive treatment, this remains low. There are a number of possible explanations for low usage, including a lack of medical provider insight into the need for preventive medications and inadequate treatment response or intolerable side effects with currently available treatment options. Studies have shown that adherence with migraine preventive therapy is low in clinical practice. ${ }^{18}$ Current, or ever use of preventive medications, did not differ significantly by country in unadjusted or adjusted analyses, suggesting that the proportion of migraineurs who receive preventive therapy is similar, despite differences in frequency of outpatient and inpatient visits. Antidepressants were the most commonly reported prophylaxis agents used, except for EM patients in Germany, despite guideline recommendations for using $\beta$ blockers and antiepileptics first line. ${ }^{19}{ }^{20}$ The reason for this is unknown, though it may be influenced by insurance coverage, physician experience, patient comorbidities (eg, depression or insomnia) or simply poor adherence with guidelines. Additionally, antidepressants are used for tension-type headaches as well, and may be prescribed if the diagnosis is uncertain. ${ }^{21}$ Finally, due to the cross-sectional design, the sample is not limited to those initiating prophylaxis therapy for the first time, so many respondents had tried multiple agents. Use of prescription-acute treatments differed significantly across

Table 5 Typical provider of headache care in chronic and episodic migraine

\begin{tabular}{|c|c|c|c|c|c|c|c|}
\hline \multirow{3}{*}{$\begin{array}{l}\text { Provider type } \\
\text { n }(\%)^{*}\end{array}$} & USA & Canada & France & UK & Germany & Australia & \multirow[b]{3}{*}{ p Value } \\
\hline & \multicolumn{6}{|c|}{ Chronic migraine } & \\
\hline & $(n=205)$ & $(n=50)$ & $(n=57)$ & $(n=50)$ & $(n=81)$ & $(n=50)$ & \\
\hline Primary care & $130(63)$ & $28(56)$ & $44(77)$ & 37 (74) & $51(63)$ & $44(88)$ & 0.003 \\
\hline Chiropractor & $20(10)$ & $5(10)$ & $0(0)$ & $0(0)$ & $1(1)$ & $7(14)$ & 0.001 \\
\hline Internist & $11(5)$ & $0(0)$ & $1(2)$ & $0(0)$ & $9(11)$ & $0(0)$ & 0.004 \\
\hline Neurologist & $49(24)$ & $10(20)$ & $10(17)$ & 7 (14) & $24(30)$ & 7 (14) & 0.171 \\
\hline Pain specialist & $9(4)$ & $4(8)$ & $4(7)$ & $3(6)$ & $11(14)$ & $5(10)$ & 0.157 \\
\hline Othert & $20(10)$ & $5(10)$ & $9(16)$ & $2(4)$ & $14(17)$ & $8(16)$ & 0.157 \\
\hline \multirow[t]{3}{*}{ No typical provider } & $28(14)$ & $6(12)$ & $5(9)$ & $8(16)$ & $8(10)$ & $2(4)$ & 0.379 \\
\hline & \multicolumn{6}{|c|}{ Episodic migraine } & \\
\hline & $(n=226)$ & $(n=55)$ & $(n=109)$ & $(n=107)$ & $(n=112)$ & $(n=63)$ & \\
\hline Primary care & $130(57)$ & $38(69)$ & $81(74)$ & $75(70)$ & $73(65)$ & $42(67)$ & 0.043 \\
\hline Chiropractor & $17(7)$ & $2(4)$ & $1(1)$ & $1(1)$ & $7(6)$ & $8(13)$ & 0.003 \\
\hline Internist & $14(6)$ & $2(4)$ & $0(0)$ & $0(0)$ & $11(10)$ & $1(2)$ & 0.001 \\
\hline Neurologist & $20(9)$ & $10(18)$ & 19 (17) & $2(2)$ & $19(17)$ & $3(5)$ & $<0.001$ \\
\hline Pain specialist & $3(1)$ & $0(0)$ & $3(3)$ & $1(1)$ & $4(4)$ & $0(0)$ & 0.319 \\
\hline Othert & $14(6)$ & $3(5)$ & $12(11)$ & $6(6)$ & $8(7)$ & $5(8)$ & 0.633 \\
\hline No typical provider & $60(26)$ & $11(20)$ & $18(16)$ & $25(23)$ & $24(21)$ & $13(20)$ & 0.439 \\
\hline
\end{tabular}

* Subjects may be visiting more than one provider type.

tIncludes obstetrics/gynaecology, ophthalmologist, psychiatrist, other and unknown. 




Figure 3 Typical provider of headache care by country. Subjects may be visiting more than one provider type. *Includes obstetrics/gynecology, ophthalmologist, psychiatrist, other and unknown.

countries; respondents from France, the UK, Germany and Australia were significantly more likely than those from the USA to report currently using a prescription-acute treatment.

This study has several limitations. First, it has limited ability to explain variability because country-level variables were not included in the dataset. For example, it is unclear whether having fewer recent provider visits in one country relative to another is an indication of poor access (eg, because of affordability), better control of migraines, or some other factor that varies across countries. Due to the cross-sectional design, the results include prevalent cases of migraine. Treatment patterns for incident migraine, including time to treatment and treatment duration, cannot be assessed. Additionally, results depend upon respondent recall and report, since data were not verified through external sources. However, misclassification is likely to be non-differential; there is no reason to believe that country of residence is associated with recall of resource usage. Misclassification of headache type may have occurred as well, due to reliance upon patient recall of headache days in the past 3 months, and exclusion of the ICHD-IIR criteria requiring eight or more migraine days per month, and absence of medication overuse, headache, or other causative disorder. ${ }^{1}$

Generalisability to the broader global migraine population may be limited. The sample was selected from a pool of individuals who elected to participate in web-based health-related surveys, and likely had a higher average education level than the general population, since literacy and internet access were required. Health status and access to care are strongly associated with education level, so this is a major limitation. However, sociodemographic characteristics of US respondents are similar in many respects to those from AMPP. ${ }^{8}$ For example, respondents were primarily Caucasian and female in both EM (percent Caucasian: IBMS-II 88\%, AMPP 87\%; percent female: IBMS-II 80\%, AMPP 80\%) and CM (percent Caucasian: IBMS-II 87\%, AMPP 91\%; percent female: IBMS-II 81\%, AMPP 79\%). However, though average age was fairly similar between the two studies, IBMS-II respondents were slightly younger in both EM (mean age: IBMS-II 44, AMPP 46) and CM (mean age: IBMS-II 44, AMPP 48). Also, fewer IBMS-II respondents reported being currently employed full or part time in both EM (IBMS-II 55\%, AMPP 65\%) and CM (IBMS-II 38\%, AMPP 49\%).

Overall, the results presented here suggest that chronic and episodic migraineurs differ across countries sociodemographically, clinically and in resources used. US migraineurs were generally less likely to report recent provider visits and use of prescription-acute treatments. They were also more likely to report ED visits than the European countries, but less likely to report hospitalisation than Canada and Australia. Further research into the sources of this variability, including the influence of healthcare system design, supply and demand

Table 6 Adjusted odds of using resources by country, relative to the USA

\begin{tabular}{|c|c|c|c|c|c|c|}
\hline OR $(95 \% \mathrm{Cl})^{*}$ & USA & Canada & France & UK & Germany & Australia \\
\hline $\begin{array}{l}\text { Have visited a provider for headache in the last } \\
3 \text { months }\end{array}$ & 100 & 1.79 (1.07 to 2.99$)$ & 1.61 (1.04 to 2.48$)$ & 1.59 (1.02 to 2.47$)$ & $1.43(0.92$ to 2.22$)$ & 2.77 (1.71 to 4.47$)$ \\
\hline Have a typical provider of headache care & 1.00 & 1.64 (0.83 to 3.26$)$ & 1.85 (1.04 to 3.32$)$ & $1.03(0.62$ to 1.73$)$ & $1.59(0.90$ to 2.79$)$ & $1.93(0.98$ to 3.79$)$ \\
\hline Have visited the emergency department for headache & 1.00 & 1.32 (0.81 to 2.18$)$ & $0.37(0.22$ to 0.62$)$ & $0.25(0.14$ to 0.45$)$ & 0.31 (0.18 to 0.53$)$ & $0.89(0.55$ to 1.45$)$ \\
\hline Have been admitted to the hospital for headache & 1.00 & 2.18 (1.11 to 4.27$)$ & $1.66(0.90$ to 3.08$)$ & $0.56(0.23$ to 1.32$)$ & 1.54 (0.81 to 2.91$)$ & $2.16(1.14$ to 4.12$)$ \\
\hline Have ever tried more than three preventive treatments & 1.00 & 0.75 (0.38 to 1.47$)$ & $0.89(0.50$ to 1.58$)$ & 1.21 (0.69 to 2.12$)$ & 0.79 (0.44 to 1.41$)$ & $0.82(0.43$ to 1.56$)$ \\
\hline Currently using more than one preventive treatment & 1.00 & $0.51(0.17$ to 1.55$)$ & 1.24 (0.58 to 2.63$)$ & $1.63(0.77$ to 3.44$)$ & $0.74(0.33$ to 1.69$)$ & $1.10(0.47$ to 2.58$)$ \\
\hline Ever tried more than 3 acute treatments & 1.00 & 0.77 (0.43 to 1.38$)$ & 2.18 (1.21 to 3.90$)$ & $1.40(0.83$ to 2.36$)$ & 1.67 (0.96 to 2.91$)$ & $1.62(0.86$ to 3.04$)$ \\
\hline Currently using a prescription acute treatment & 1.00 & $1.14(0.70$ to 1.86$)$ & 1.80 (1.19 to 2.74$)$ & $2.68(1.72$ to 4.17$)$ & 2.10 (1.37 to 3.23$)$ & $1.88(1.16$ to 3.03$)$ \\
\hline
\end{tabular}

${ }^{*}$ OR (relative to USA) are adjusted for age, gender, income, race/ethnicity, region of residence, employment status, BMI, migraine type and number of comorbid conditions. 
features and the impact of this variability on outcomes is warranted.

Acknowledgements The authors would also like to thank the following individuals for their contributions: G Maglinte (Amgen, Inc) and L Liu (Allergan, Inc) for contributing to experimental design, and L Allen, K Payne, I Proskorovsky, $\mathrm{K}$ Yeomans, R Yu (United BioSource Corporation, Bethesda, Maryland, USA) for data collection.

Contributors JCS (guarantor) developed the research question, planned and conducted the data analysis, and drafted and revised the manuscript. EBD, SDS and LMB assisted in research question development and reviewed and revised the analysis plan and manuscript. SFV designed the second International Burden of Migraine Study, assisted in research question development and reviewed and revised the analysis plan and manuscript. RBL, AMB, PJG and DCB designed the second International Burden of Migraine Study and reviewed and revised the manuscript.

Funding The study sponsor (Allergan, Inc) was involved in the study design, data collection, data analysis, data interpretation, and the writing of the article. The sponsor and corresponding authors directed the research design and reviewed all major research decisions (ie, study instruments, sampling and analyses). The authors had full access to all data and had final responsibility for the decision to submit for publication.

Competing interests JCS is a senior fellow at Allergan, Inc. LMB and SFV are employees of Allergan, Inc. EBD and SDS indicate no conflicts of interest. RBL has received grants or honoraria from Allergan, Inc, Merck, Inc, Neuralieve, Novartis, OrthoMcNeil, the National Headache Foundation, and the National Institute of Health. ABD has received grants or honoraria from Allergan, Inc, Pfizer, Zogenix, Merck, OrthoMcNeil, MAP pharmaceuticals, Forrest, GSK, and Posen. DCB has received honoraria and/or research funding from Allergan, Inc, Merck, Inc, MAP Pharmaceuticals, NuPathe, and Novartis. PJG is on the boards of Allergan, Colucid, MAP pharmaceuticals, Merck, Sharpe and Dohme, eNeura, Neuroaxon, Autonomic Technologies Inc, Boston Scientific, Eli-Lilly, Medtronic, Linde gases, Arteaus, AlderBio and BristolMyerSquibb. He has consulted for Pfizer, Nevrocorp, Lundbeck, Zogenix, Impax and Dr Reddy, and has been compensated for expert legal testimony. He has grant support from GlaxoSmithKline, MAP, MSD, eNeura and Amgen. He has received honoraria for speaking from MSD, Pfizer, Allergan and Mennarini, and payment for editorial work from Journal Watch Neurology, and for developing educational materials for the American Headache Society.

Provenance and peer review Not commissioned; externally peer reviewed.

Open Access This is an Open Access article distributed in accordance with the Creative Commons Attribution Non Commercial (CC BY-NC 3.0) license, which permits others to distribute, remix, adapt, build upon this work non-commercially, and license their derivative works on different terms, provided the original work is properly cited and the use is non-commercial. See: http://creativecommons.org/ licenses/by-nc/3.0/

\section{REFERENCES}

1 Olesen J, Bousser MG, Diener HC, et al.; Headache Classification Committee. New appendix criteria open for a broader concept of chronic migraine. Cephalalgia 2006;26:742-6.

2 Headache Classification Committee of The International Headache Society. The international classification of headache disorders (second edition). Cephalalgia 2004;24(Suppl 1):1-160.
3 Natoli JL, Manack A, Dean B, et al. Global prevalence of chronic migraine: a systematic review. Cephalalgia 2010;30:599-609.

4 Buse DC, Manack AN, Fanning KM, et al. Chronic migraine prevalence, disability, and sociodemographic factors: results from the American Migraine Prevalence and Prevention Study. Headache 2012;52:1456-70.

5 Blumenfeld AM, Varon SF, Wilcox TK, et al. Disability, HRQoL and resource use among chronic and episodic migraineurs: results from the International Burden of Migraine Study (IBMS). Cephalalgia 2011;31:301-15.

6 Buse D, Manack A, Serrano D, et al. Headache impact of chronic and episodic migraine: results from the American Migraine Prevalence and Prevention study. Headache 2012;52:3-17

7 Stewart WF, Wood GC, Manack A, et al. Employment and work impact of chronic migraine and episodic migraine. J Occup Environ Med 2010;52:8-14.

8 Buse DC, Manack A, Serrano D, et al. Sociodemographic and comorbidity profiles of chronic migraine and episodic migraine sufferers. J Neurol Neurosurg Psychiatry 2010;81:428-32.

9 Stokes M, Becker WJ, Lipton RB, et al. Cost of health care among patients with chronic and episodic migraine in Canada and the USA: results from the International Burden of Migraine Study (IBMS). Headache 2011;51:1058-77.

10 Bloudek LM, Stokes M, Buse DC, et al. Cost of healthcare for patients with migraine in five European countries: results from the International Burden of Migraine Study (IBMS). Headache Pain 2012;13:361-78.

11 Gerth WC, Carides GW, Dasbach EJ, et al. The multinational impact of migraine symptoms on healthcare utilisation and work loss. Pharmacoeconomics 2001:19:197-206.

12 Schoen $C$, Osborn $R$, Squires $D$, et al. How health insurance design affects access to care and costs, by income, in eleven countries. Health Aff (Millwood) 2010;29:2323-34.

13 Lightspeed Research. Lightspeed Online Research, Inc. c 2012 [cited 29 April 2012]. http://www.lightspeedresearch.com

14 STATA Data Analysis and Statistical Software. STATA Release 12. College Station, TX: StataCorp LP, c 1996-2012 [cited 29 April 2012]. http://www.stata.com

15 Stewart WF, Lipton RB, Dowson AJ, et al. Development and testing of the Migraine Disability Assessment (MIDAS) Questionnaire to assess headache-related disability. Neurology 2001;56(6 Suppl 1):S20-8.

16 Payne KA, Varon SF, Kawata AK, et al. The International Burden of Migraine Study (IBMS): study design, methodology, and baseline cohort characteristics. Cephalalgia 2011;31:1116-30.

17 Diamond S, Bigal ME, Silberstein S, et al. Patterns of diagnosis and acute and preventive treatment for migraine in the United States: results from the American Migraine Prevalence and Prevention study. Headache 2007:47:355-63.

18 Berger A, Bloudek LM, Varon SF, et al. Adherence with migraine prophylaxis in clinical practice. Pain Pract 2012;12:541-9.

19 Evers S, Afra J, Frese A, et al. European Federation of Neurological Societies. EFNS guideline on the drug treatment of migraine-revised report of an EFNS task force. Eur J Neurol 2009;16:968-81.

20 Silberstein SD, Holland S, Freitag F, et al. Quality Standards Subcommittee of the American Academy of Neurology and the American Headache Society. Evidence-based guideline update: pharmacologic treatment for episodic migraine prevention in adults: report of the Quality Standards Subcommittee of the American Academy of Neurology and the American Headache Society. Neurology 2012;78:1337-45.

21 Bendtsen L, Evers S, Linde M, et al. EFNS. EFNS guideline on the treatment of tension-type headache-report of an EFNS task force. Eur J Neurol 2010;17:1318-25. 